\title{
The implementation of a FIP guidance for COVID-19: insights from a nationwide survey
}

\author{
Zhan-Miao Yi ${ }^{1,2,3 \#}$, Zai-Wei Song ${ }^{1,2,3 \#}$, Xin-Ya Li ${ }^{1,2,3,4}$, Yang Hu ${ }^{1,2,3,4}$, Yin-Chu Cheng ${ }^{1,2,3}$, \\ Guan-Ru Wang ${ }^{1,2,3,4}$, Rong-Sheng Zhao ${ }^{1,2,3}$ \\ ${ }^{1}$ Department of Pharmacy, Peking University Third Hospital, Beijing, China; ${ }^{2}$ Institute for Drug Evaluation, Peking University Health Science \\ Center, Beijing, China; ${ }^{3}$ Therapeutic Drug Monitoring and Clinical Toxicology Center, Peking University, Beijing, China; ${ }^{4}$ Department of Pharmacy \\ Administration and Clinical Pharmacy, School of Pharmaceutical Sciences, Peking University, Beijing, China \\ Contributions: (I) Conception and design: ZM Yi, ZW Song, RS Zhao; (II) Administrative support: ZM Yi, ZW Song, RS Zhao; (III) Provision of \\ study materials or patients: ZM Yi, ZW Song; (IV) Collection and assembly of data: ZM Yi, ZW Song, XY Li; (V) Data analysis and interpretation: \\ XY Li, Y Hu, YC Cheng, GR Wang; (VI) Manuscript writing: All authors; (VII) Final approval of manuscript: All authors. \\ \#These authors contributed equally to this work. \\ Correspondence to: Rong-Sheng Zhao. Department of Pharmacy, Peking University Third Hospital, 49 North Garden Road, Haidian District, Beijing, \\ China. Email: zhaorongsheng@bjmu.edu.cn.
}

\begin{abstract}
Background: The International Pharmaceutical Federation (FIP) has established an interim guidance of coronavirus disease 2019 (COVID-19) for pharmacists worldwide. The aim of this study was to identify the implementation of FIP guidance in China and provide applicable strategies for further actions.

Methods: A nationwide cross-sectional survey on Chinese pharmacists was distributed electronically through groups of WeChat between 9 December 2020 and 18 December 2020. The 29-item questionnaire for the survey was designed based on the FIP guidance and knowledge, attitudes, and practices (KAP) framework.
\end{abstract}

Results: A total of 237 responses from 237 pharmacists (69.20\% females) were received. Most pharmacists (81.86\%) participated in work related to COVID-19. Respondents referred to other guidelines or consensus more than they did to FIP guidance. Most participants were qualified for the knowledge-based questions regarding COVID-19 (67.51\%), had positive attitudes towards pharmacists' roles and actions (61.18\%), and were qualified in the practices of prevention measures, infection risk monitoring, and pharmacists' advice (50.63\%). Several factors were revealed as having impact on pharmacists' KAP, such as the relevance of participating in work related to COVID-19, work entailments, and information source.

Conclusions: The FIP guidance has a certain degree of dissemination and implementation in China, which can be improved through effective actions directed towards impact factors.

Keywords: Knowledge; attitudes; practices; guideline implementation; pharmacist

Submitted Jul 26, 2021. Accepted for publication Sep 18, 2021.

doi: $10.21037 / \mathrm{atm}-21-4157$

View this article at: https://dx.doi.org/10.21037/atm-21-4157

\section{Introduction}

Presently, the coronavirus disease 2019 (COVID-19) pandemic is continuing to present a prominent challenge all over the world, and seriously endangering society (1). During a pandemic, the pharmacy becomes a vital access point for medicines and healthcare advice (2). As healthcare professionals, pharmacists join the medical collaborative team and provide pharmaceutical care. In order to support pharmacists in performing their key roles, the International Pharmaceutical Federation (FIP) established an interim guidance of COVID-19 for pharmacists worldwide (3). The FIP guidance covered disease transmission, incubation period, clinical treatment, preventive measures, cleaning 
and disinfection management, responsibilities and role of pharmacy etc. in primary care, hospital settings, and medical analysis laboratories.

The dissemination and implementation of medical guidance is a global challenge, resulting in the underutilization of guidelines (4-6). The study by Sousa Pinto et al. (7) described the strategy and measures adopted by FIP in collaboration with international experts to support the effective pharmaceutical service and their important value on health systems throughout the pandemic around the world. And previous studies (8-10) have analyzed the knowledge, attitudes, and practices (KAP) of pharmacists and found their actions are largely affected by their KAP towards COVID-19. However, there is a lack of status analysis of the FIP guidance, and pharmacists' adherence to the guidance has remained ambiguous.

Thus, we investigated pharmacists' KAP towards COVID-19 by conducting a nationwide survey, aiming to identify current practices and barriers of FIP guidance, and to provide relevant strategies for further actions.

We presented the following article in accordance with the SURGE reporting checklist (available at https://dx.doi. org/10.21037/atm-21-4157).

\section{Methods}

\section{Setting and participants}

This nationwide cross-sectional survey on Chinese pharmacists has been registered on the Chinese Clinical Trial Registry (ChiCTR2000035213).

A recruitment notice was posted to groups of WeChat through authors' accounts (Yi and Song) from 9 December through 11 December 2020, which involved pharmacists come from various provinces and autonomous regions in mainland China, with different job titles and job positions. The notice contained a brief introduction including study background and funding resource, objective, procedures, voluntary nature of participation, declarations of anonymity and confidentiality, and notes for completing the questionnaire, as well as a link to the online questionnaire. To collect data of KAP from a cross section, the 18 December 2020 was set as the deadline for completion (maximum of 10 days). The recruitment notice was send out once and no incentive was provided.

All Chinese mainland pharmacists engaged in pharmacy were considered eligible, including pharmacists in hospital, community clinics, or retail pharmacy, regardless of their position, gender, or region. Two similar questions in the questionnaire were set as logic check items, which were used to assess the quality of collected questionnaires. The exclusion criteria were as follows: duplicate answer sheets from the same person; answer sheets where there were contradictory answers; partial completed questionnaires.

\section{Study instrument and measures}

The questionnaire was designed based on the FIP guidance (3) and KAP framework (11). The draft questionnaire was initiated by 3 authors (Rong-Sheng Zhao, Zhan-Miao Yi, and Zai-Wei Song) who have been actively participating in the development of FIP guidance (3) and its Chinese version (12). Senior pharmacy experts and epidemiology experts were consulted, and the questionnaire was pre-filled by students and pharmacists who did not then participate in this study. The final survey questionnaire was assessed and modified based on expert suggestions and the results of the pre-surveys.

The questionnaire consisted of 4 parts: demographics (including COVID-19 related information), knowledge, attitudes, and practices. Demographic variables included province/region, gender, job title, education, job responsibilities, working years, job position, participation in COVID-19 work or not, COVID-19 working content, and COVID-19 information source.

The KAP questions in the questionnaire were developed based on the FIP guidance. The knowledge questionnaire had 11 questions with multiple choice and true/false options: 6 (K1-K6) regarding transmission routes, and 5 (K7-K11) regarding clinical treatment of COVID-19 (medicine, convalescent plasma treatment, and vaccines). Attitudes towards COVID-19 were measured by 13 questions: 4 (A1-A4) regarding self-confidence in the role of pharmacists, and 9 (A5-A13) regarding the agreement of measures related to "supporting pharmacists and pharmacy teams". Each question was scored from 1 to 10. The assessment of respondents' practices was composed of 5 behaviors (P1-P5), including prevention and control measures, infection risk, and pharmacists' advice.

\section{Statistical analysis}

The statistical analyses were performed with SPSS software version 26.0 (IBM Corp., Armonk, NY, USA). Multiple imputation approach was used for missing data. For quantitative data following a normal distribution, we 
calculated mean with standard deviations (mean $\pm \mathrm{SD}$ ) and used Pearson's rank correlation test to identify the possible correlation between variables. For non-normally distributed data, we calculated median with interquartile range [median (IQR)] and used Spearman's rank correlation test to test the correlation among variables. For qualitative data, we calculated frequency and constituent ratio and used the chisquared test to compare the difference between the groups. The level of knowledge, attitudes, and practices were summarized and classified. A correct rate of answers above $60 \%$ was considered "qualified", while below $60 \%$ was considered "unqualified". A score of attitudes above 9 was considered "positive", while below 9 was considered "not positive".

We used a logistic regression model to identify independent factors of KAP. Empirically, each co-variable needs at least 10 participants in logistic regression models, thus at least 90 responses was required for 9 co-variables in the survey. Univariate analysis was performed for all baseline and COVID-19-related characteristics. Variables with statistical significance as well as gender, professional title, the highest education degree, job duties, length of working years, and operating post (determined by reading relevant literature and combining clinical experience) were included in the multivariate logistic regression using the Enter method. The level of statistical significance was set at $\mathrm{P}<0.05$ (2-tailed analysis).

\section{Ethical approval}

All procedures performed in this study involving human participants were in accordance with the Declaration of Helsinki (as revised in 2013). The study was approved by institutional ethics board of Peking University Third Hospital (No. IRB00006761-M2020299). The online voluntary and anonymous questionnaire secured the confidentiality of the participants, and did not collect any identity-exposing information of the participants.

\section{Results}

\section{Basic information}

During the study period, 237 responses from 237 pharmacists were received, and all met the inclusion criteria. Among all respondents, 69.20\% were females. Pharmacists were from various regions of mainland China, including Northwest (39.66\%), North (18.57\%), Central
(16.46\%), Southwest (8.86\%), South (7.17\%), Northeast (5.91\%), and East China (3.38\%). Among the included pharmacists, $93.67 \%$ held a bachelor's degree or above, and $78.06 \%$ has been working as a pharmacist for more than 5 years.

During the pandemic, 194 pharmacists $(81.86 \%)$ participated in COVID-19 related work, such as drug supply and guarantee, pharmacy information support, drug dispensation, and guidelines/consensus development. The main information source for COVID-19 was in-hospital training, followed by National Health Commission and other official guidance documents, and other guidelines or consensus. Among the included pharmacists, $48.95 \%$ had studied the FIP guidance. Demographics of pharmacists and COVID-19-related information are shown in Table 1.

\section{Knowledge: transmission routes and clinical treatment}

The knowledge questionnaire consisted of 2 parts with 11 questions (K1-K11): transmission routes and clinical treatment of COVID-19 (answers are shown in Figure 1). Overall, the number of correct answers was 7 [2] \{median [IQR]\}, and $67.51 \%$ of respondents were classified as qualified. In terms of transmission routes (K1-K6), most pharmacists answered correctly; however, the correct answer rate of $\mathrm{K} 3$ on pregnant or lactating patients with COVID-19 was only $11.81 \%$. The correct rate of the application of convalescent plasma therapy (K9) was $23.63 \%$. The working content of COVID-19 "drug dispensation" (negative correlation) and the information source of COVID-19 "other guidelines or consensus" (positive correlation) were statistically significant independent factors in both univariate and multivariate logistic regression analysis (Table 2).

\section{Attitudes: pharmacists' roles and actions}

Overall, 145 pharmacists (61.18\%) were classified as having positive attitudes. The score of pharmacists' roles and actions was 9.2 [1.4] \{median [IQR]\}. The scores of the attitudes section are shown in Figure 2. When asked to grade their self-confidence in the role of pharmacists (A1A4), 129 participants (54.43\%) displayed positive attitudes. Compared with pharmacists' role in clinical management of COVID-19 \{median [IQR]: 9 [2]\}, pharmacists were more confident about their role in relevant research \{median [IQR]: 10 [2]\}. As for the agreement of measures related to "supporting pharmacists and pharmacy teams" (A5-A13), 
Table 1 Demographics of pharmacists and COVID-19-related information

\begin{tabular}{|c|c|c|c|}
\hline Characteristics & Subgroup & $\mathrm{n}$ & $\%$ \\
\hline \multirow[t]{2}{*}{ Gender } & Female & 164 & 69.20 \\
\hline & Male & 73 & 30.80 \\
\hline \multirow[t]{3}{*}{ Job title } & Primary and below & 62 & 26.16 \\
\hline & Junior & 104 & 43.88 \\
\hline & Senior & 71 & 29.96 \\
\hline \multirow{4}{*}{$\begin{array}{l}\text { Education } \\
\text { background }\end{array}$} & College and below & 15 & 6.33 \\
\hline & Bachelor & 128 & 54.01 \\
\hline & Master & 71 & 29.96 \\
\hline & Doctor & 23 & 9.70 \\
\hline \multirow{4}{*}{$\begin{array}{l}\text { Job } \\
\text { responsibility }\end{array}$} & Clinical pharmacist & 114 & 48.10 \\
\hline & Drug dispensing & 59 & 24.89 \\
\hline & Pharmacy administrator & 47 & 19.83 \\
\hline & Others $^{a}$ & 17 & 7.17 \\
\hline \multirow[t]{5}{*}{ Working years } & $1-5$ & 52 & 21.94 \\
\hline & $6-10$ & 69 & 29.11 \\
\hline & $11-15$ & 48 & 20.25 \\
\hline & $16-20$ & 20 & 8.44 \\
\hline & $\geq 21$ & 48 & 20.25 \\
\hline \multirow{6}{*}{$\begin{array}{l}\text { Job position } \\
\text { (multiple } \\
\text { choice) }\end{array}$} & General clinic & 83 & 35.02 \\
\hline & General ward & 77 & 32.49 \\
\hline & General emergency & 32 & 13.50 \\
\hline & Fever clinic & 19 & 8.02 \\
\hline & $\begin{array}{l}\text { Isolation ward or Fangcang } \\
\text { Shelter }\end{array}$ & 8 & 3.38 \\
\hline & Others $^{b}$ & 104 & 43.88 \\
\hline \multirow{2}{*}{$\begin{array}{l}\text { COVID-19 } \\
\text { work }\end{array}$} & Participation & 194 & 81.86 \\
\hline & No participation & 43 & 18.14 \\
\hline \multirow{7}{*}{$\begin{array}{l}\text { Working } \\
\text { content of } \\
\text { COVID-19 } \\
\text { (multiple } \\
\text { choice) }\end{array}$} & Drug supply and guarantee & 94 & 39.66 \\
\hline & $\begin{array}{l}\text { Pharmacy information } \\
\text { support }\end{array}$ & 87 & 36.71 \\
\hline & Drug dispensation & 86 & 36.29 \\
\hline & Drug evaluation & 31 & 13.08 \\
\hline & Disinfectant preparation & 23 & 9.70 \\
\hline & $\begin{array}{l}\text { Guidelines/consensus } \\
\text { development }\end{array}$ & 14 & 5.91 \\
\hline & Others $^{c}$ & 69 & 29.11 \\
\hline
\end{tabular}

Table 1 (continued)
Table 1 (continued)

\begin{tabular}{|c|c|c|c|}
\hline Characteristics & Subgroup & $\mathrm{n}$ & $\%$ \\
\hline \multirow{8}{*}{$\begin{array}{l}\text { Information } \\
\text { source of } \\
\text { covID-19 } \\
\text { (multiple } \\
\text { choice) }\end{array}$} & In-hospital training & 208 & 87.76 \\
\hline & $\begin{array}{l}\text { National Health } \\
\text { Commission and } \\
\text { other official guidance } \\
\text { documents }\end{array}$ & 194 & 81.86 \\
\hline & Other guidelines/consensus & 165 & 69.62 \\
\hline & News media & 145 & 61.18 \\
\hline & FIP guidance & 116 & 48.95 \\
\hline & Journal articles & 107 & 45.15 \\
\hline & Academic conferences & 90 & 37.97 \\
\hline & Others $^{d}$ & 17 & 7.17 \\
\hline \multicolumn{4}{|c|}{$\begin{array}{l}\text { a, laboratory pharmacist (TDM and genetic testing), prescription } \\
\text { reviews, drug information pharmacist, etc.; }{ }^{b} \text {, other departments } \\
\text { of drug supply and guarantee, pharmacy laboratory (TDM and } \\
\text { genetic testing), clinical trial institution, quality control, etc.; }{ }^{\text {, }} \\
\text { pharmacy consultation, popular science writing, conducting } \\
\text { related research, laboratory nucleic acid testing, infection } \\
\text { control work, etc.; ' } \text {, municipal continuation education projects, } \\
\text { clinical management of COVID-19 patients, etc.; COVID-19, } \\
\text { coronavirus disease 2019; TDM, therapeutic drug monitoring; } \\
\text { FIP, International Pharmaceutical Federation. }\end{array}$} \\
\hline
\end{tabular}

the median (IQR) was 9.4 (1.4). Among items A5-A13, the item "Recognize pharmacists as pivotal anti-epidemic staff" (A5) returned the lowest score of 8.0 (3.0). The COVID-19 information source "the National Health Commission and other official guidance documents" was identified as a significant positive impact factor in both univariate and multivariate logistic regression analysis (Table 3).

\section{Practices: prevention, control measures, and pharmacist's advice}

The assessment of practices was composed of 5 behaviors (P1-P5). Answers to the knowledge section are shown in Figure 3. The number of correct answers was 3 [1] \{median [IQR]\}, and $50.63 \%$ of pharmacists were classified as qualified. The incorrect answers were mainly focused on disinfectant. Among them, 78.90\% (P2) and $60.76 \%$ pharmacists $(\mathrm{P} 4)$ believed that chlorhexidine could effectively inactivate the severe acute respiratory syndrome coronavirus 2 (SARS-CoV-2). Additionally, $23.21 \%$ pharmacists held that $75 \%$ ethanol could be used to disinfect large areas such as the air. The job position 


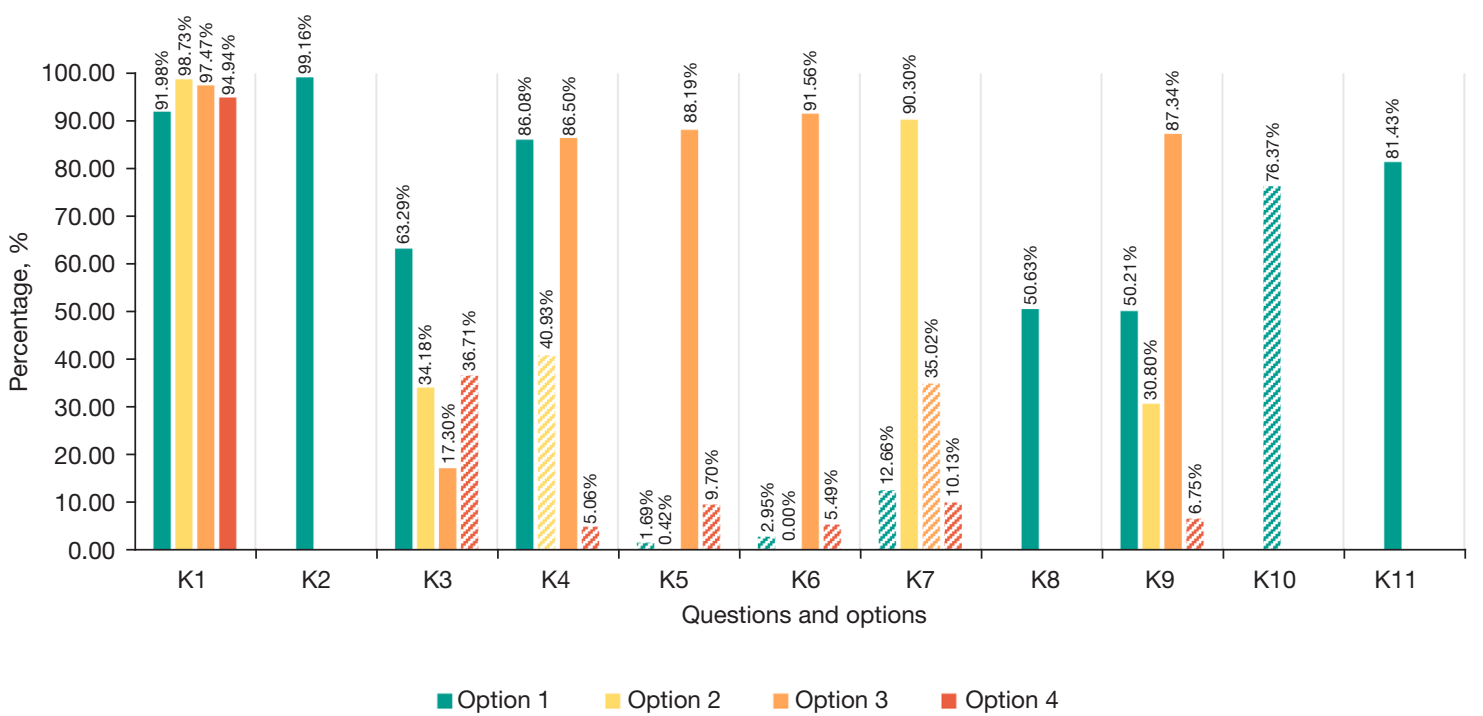

Figure 1 Results of knowledge. K1—which statement about the transmission of the virus is correct: (correct) the most common way of transmission is close contact between people; (correct) human-to-human transmission occurs mainly through droplets produced when the infected person speaks, coughs or sneezes; (correct) droplets from patients infected with COVID-19 may fall on the mouth, nose, and eyes of people around, or be inhaled into the lungs; (correct) COVID-19 can be transmitted by touching the surface or object on which the virus is attached, and then touching your mouth, nose, or eyes. K2-(correct) the virus can be transmitted by infected patients with or without symptoms, is it correct? K3-which of the following statements about people during pregnancy and lactation is correct: (correct) for pregnant women, the mother-to-child transmission of the virus during pregnancy and perinatal period is still unclear; (correct) no virus has been detected in breast milk of breastfeeding women infected with COVID-19; (correct) mothers with COVID-19 can breastfeed; none of the above is correct. K4-which statement about COVID-19 patients is correct: (correct) COVID-19 patients may still be infectious for 2 weeks after their symptoms resolve; COVID-19 patients are unlikely to be infected again within a short period of time after recovery; (correct) most infected people with symptoms will develop symptoms within 14 days of exposure; none of the above is correct. K5-if you have recently been in contact with a confirmed or suspected COVID-19 case and/or have a recent travel history to affected areas, at least how long is it recommended to implement strict quarantine: 7 days; 10 days; (correct) 14 days; 21 days. K6 —which statement about respiratory droplets and contact transmission is correct: the virus can only be transmitted through respiratory droplets; the virus can only be transmitted through contact; (correct) respiratory droplets and contact can transmit the virus; none of the above is correct. K7-which of the following statements about COVID-19 clinical treatment is correct? There are currently specific therapeutic drugs for COVID-19; (correct) at present, antiviral therapy is mainly used, and symptomatic and supportive treatment is carried out according to the patient's clinical situation; glucocorticoids can be routinely used to treat COVID-19; None of the above is correct. K8-(correct) COVID-19 patients taking ACEI or ARB drugs should continue to take the drug, is it correct? K9-which of the following statements about convalescent plasma therapy (CPT) are correct: (correct) convalescent plasma therapy has been successfully used in the treatment of atypical pneumonia (SARS); (correct) convalescent plasma therapy has been successfully used for the treatment of influenza A H1N1; (correct) for COVID-19 patients whose disease is progressing rapidly, severely or critically, convalescent plasma therapy can be tried; none of the above is correct. K10-(false) anti-pneumonia vaccines (such as Streptococcus pneumoniae vaccine or Haemophilus influenzae type B vaccine) can prevent COVID-19, is it correct? $\mathrm{K} 11$ - (correct) glucocorticoids are not recommended for routine use in viral pneumonia or acute respiratory distress syndrome, is it correct? COVID-19, coronavirus disease 2019; SARS, severe acute respiratory syndrome.

"others" (positive correlation), participation in COVID-19 work (positive correlation), and the COVID-19 information source "others" (negative correlation) were statistically significant independent factors in both univariate and multivariate logistic regression analysis
(Table 4).

\section{Correlation between knowledge, attitudes, and practices}

The chi-squared $\left(\chi^{2}\right)$ test was performed to evaluate the 
Table 2 Logistic regression for being qualified in knowledge

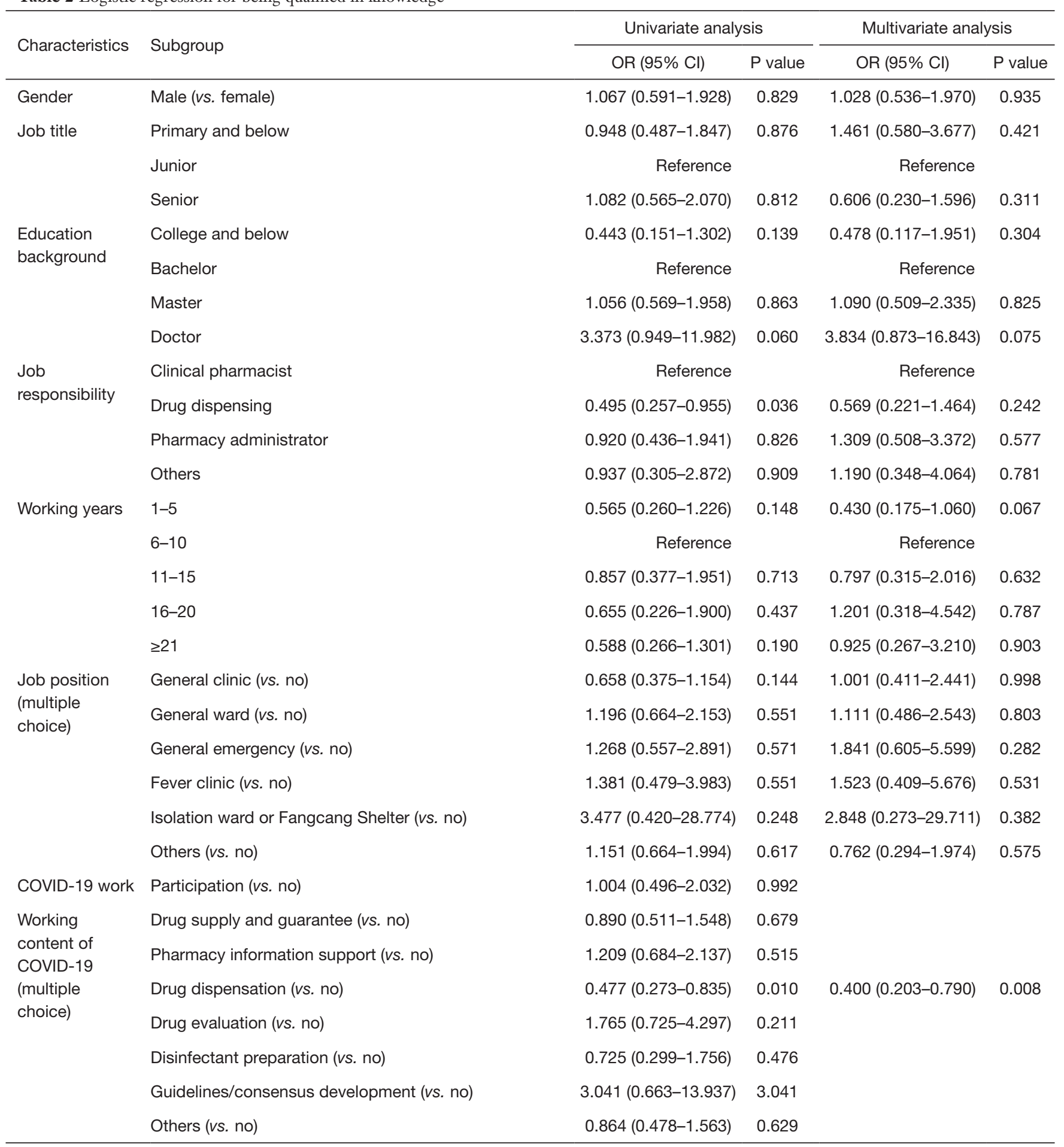

Table 2 (continued) 
Table 2 (continued)

\begin{tabular}{|c|c|c|c|c|c|}
\hline Characteristics & Subgroup & \multicolumn{2}{|c|}{ Univariate analysis } & \multicolumn{2}{|c|}{ Multivariate analysis } \\
\hline \multirow{5}{*}{$\begin{array}{l}\text { Information } \\
\text { source of } \\
\text { COVID-19 } \\
\text { (multiple choice) }\end{array}$} & In-hospital training (vs. no) & $0.926(0.401-2.143)$ & 0.858 & & \\
\hline & $\begin{array}{l}\text { National Health Commission and other official guidance } \\
\text { documents (vs. no) }\end{array}$ & $1.647(0.836-3.248)$ & 0.149 & & \\
\hline & FIP guidance (vs. no) & $1.330(0.770-2.296)$ & 0.307 & & \\
\hline & Journal articles (vs. no) & $1.061(0.614-1.834)$ & 0.831 & & \\
\hline & Academic conferences (vs. no) & $0.800(0.459-1.395)$ & 0.431 & & \\
\hline
\end{tabular}

COVID-19, coronavirus disease 2019; OR, odds ratio; Cl, confidence interval.

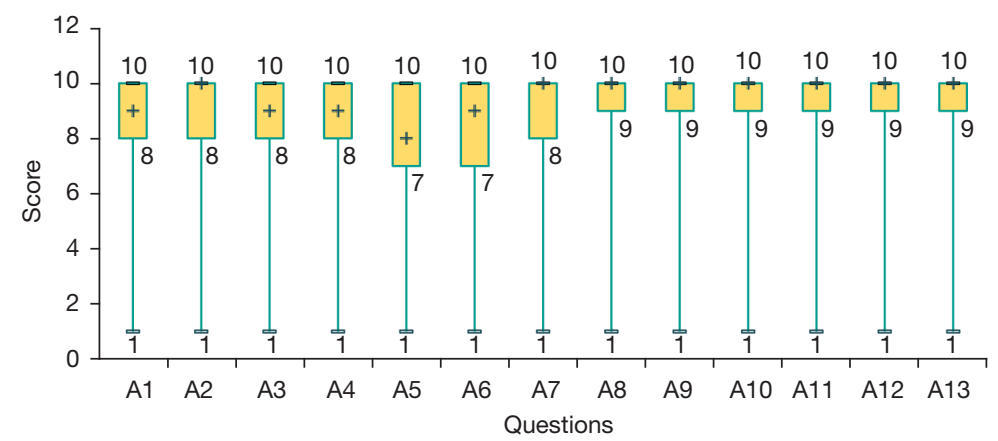

Figure 2 Results of attitudes. Please score the degree of self-confidence for the following pharmacists' roles: A1—pharmacists should actively participate in the diagnosis and treatment of COVID-19; A2 - pharmacists should actively participate in COVID-19 research; A3pharmacists can play a role in the diagnosis and treatment of COVID-19; A4-pharmacists can play a role in COVID-19 research. Please score the agreement of the following measures of "supporting pharmacists and pharmacy teams": A5-recognize pharmacists as pivotal anti-epidemic staff; A6-widely speak out to encourage the deployment of pharmacists to the frontline of the epidemic; A7-encourage to give full play of the expertise of pharmaceutical scientists and pharmacists, participate in vaccine and drug research and development, and provide evidence-based treatment information; A8-encourage all pharmacy-related practitioners to unite and cope with the global pandemic of COVID-19; A9-encourage pharmacists to continue to provide pharmaceutical services, and allow remote pharmaceutical services when necessary (such as remote pharmaceutical consultation, home delivery of medicines, etc.); A10—ensure that the pharmacist can obtain the necessary prevention and control equipment; A11-provide pharmacists with the latest, most accurate, and comprehensive clinical information related to COVID-19; A12 - carry out continuing education related to infectious diseases and emergency response to ensure that pharmacists have a timely grasp of the latest clinical and policy information; A13 — provide pharmacists with necessary support, including logistics, funding, viral nucleic acid testing, mental health guidance, etc. COVID-19, coronavirus disease 2019.

correlation between knowledge and attitudes (K\&A), knowledge and practices (K\&P), and attitudes and practices (A\&P). No significant correlation was observed in any of these pairings (K\&A: $\chi^{2}=1.368, \mathrm{P}=0.242 ; \mathrm{K} \& \mathrm{P}: \chi^{2}=0.312$, $\left.\mathrm{P}=0.577 ; \mathrm{A} \& \mathrm{P}: \chi^{2}=1.492, \mathrm{P}=0.222\right)$.

\section{Discussion}

Currently, the important role of pharmacist and innovative strategies of pharmacy interventions have been widely established and published. However, the information on the dissemination and implementation of guidance for 
Table 3 Logistic regression for being positive in attitudes

\begin{tabular}{|c|c|c|c|c|c|}
\hline Characteristics & Subgroup & \multicolumn{2}{|c|}{ Univariate analysis } & \multicolumn{2}{|c|}{ Multivariate analysis } \\
\hline Gender & Male (vs. female) & $1.353(0.772-2.371)$ & 0.291 & $1.240(0.680-2.259)$ & 0.483 \\
\hline \multirow[t]{2}{*}{ Job title } & Primary and below & 1.345 (0.706-2.562) & 0.368 & $1.463(0.628-3.407)$ & 0.378 \\
\hline & Junior & \multicolumn{2}{|l|}{ Reference } & \multicolumn{2}{|l|}{ Reference } \\
\hline \multirow{4}{*}{$\begin{array}{l}\text { Education } \\
\text { background }\end{array}$} & College and below & $0.686(0.234-2.010)$ & 0.492 & $0.951(0.239-3.779)$ & 0.943 \\
\hline & Bachelor & \multicolumn{2}{|l|}{ Reference } & \multicolumn{2}{|l|}{ Reference } \\
\hline & Master & $0.869(0.480-1.573)$ & 0.643 & $1.012(0.497-2.063)$ & 0.973 \\
\hline & Doctor & $1.125(0.444-2.850)$ & 0.804 & $1.269(0.415-3.883)$ & 0.676 \\
\hline \multirow{2}{*}{$\begin{array}{l}\text { Job } \\
\text { responsibility }\end{array}$} & Pharmacy administrator & 1.409 (0.694-2.862) & 0.343 & $1.222(0.523-2.855)$ & 0.643 \\
\hline & Others & $0.646(0.233-1.797)$ & 0.403 & $0.748(0.248-2.250)$ & 0.605 \\
\hline \multirow[t]{5}{*}{ Working years } & $1-5$ & 1.008 (0.484-2.099) & 0.983 & $1.012(0.442-2.318)$ & 0.978 \\
\hline & $6-10$ & \multicolumn{2}{|l|}{ Reference } & \multicolumn{2}{|l|}{ Reference } \\
\hline & $11-15$ & $1.042(0.491-2.211)$ & 0.914 & $1.025(0.448-2.347)$ & 0.953 \\
\hline & $16-20$ & $1.024(0.371-2.828)$ & 0.963 & $0.956(0.280-3.267)$ & 0.943 \\
\hline & $\geq 21$ & 1.366 (0.633-2.946) & 0.427 & $1.084(0.346-3.4030$ & 0.890 \\
\hline $\begin{array}{l}\text { Job position } \\
\text { (multiple choice) }\end{array}$ & General clinic (vs. no) & $1.289(0.741-2.243)$ & 0.369 & $1.397(0.603-3.237)$ & 0.435 \\
\hline COVID-19 work & Participation (vs. no) & 1.037 (0.528-2.040) & 0.915 & & \\
\hline \multirow{7}{*}{$\begin{array}{l}\text { Working content } \\
\text { of COVID-19 } \\
\text { (multiple choice) }\end{array}$} & Drug supply and guarantee (vs. no) & $1.298(0.758-2.225)$ & 0.342 & & \\
\hline & Pharmacy information support (vs. no) & $1.146(0.665-1.975)$ & 0.624 & & \\
\hline & Drug dispensation (vs. no) & $1.030(0.598-1.774)$ & 0.915 & & \\
\hline & Drug evaluation (vs. no) & $0.861(0.400-1.854)$ & 0.703 & & \\
\hline & Disinfectant preparation (vs. no) & $1.212(0.299-1.756)$ & 0.676 & & \\
\hline & Guidelines/consensus development (vs. no) & $1.151(0.374-3.550)$ & 0.806 & & \\
\hline & Others (vs. no) & $1.275(0.711-2.285)$ & 0.414 & & \\
\hline
\end{tabular}

Table 3 (continued) 
Table 3 (continued)

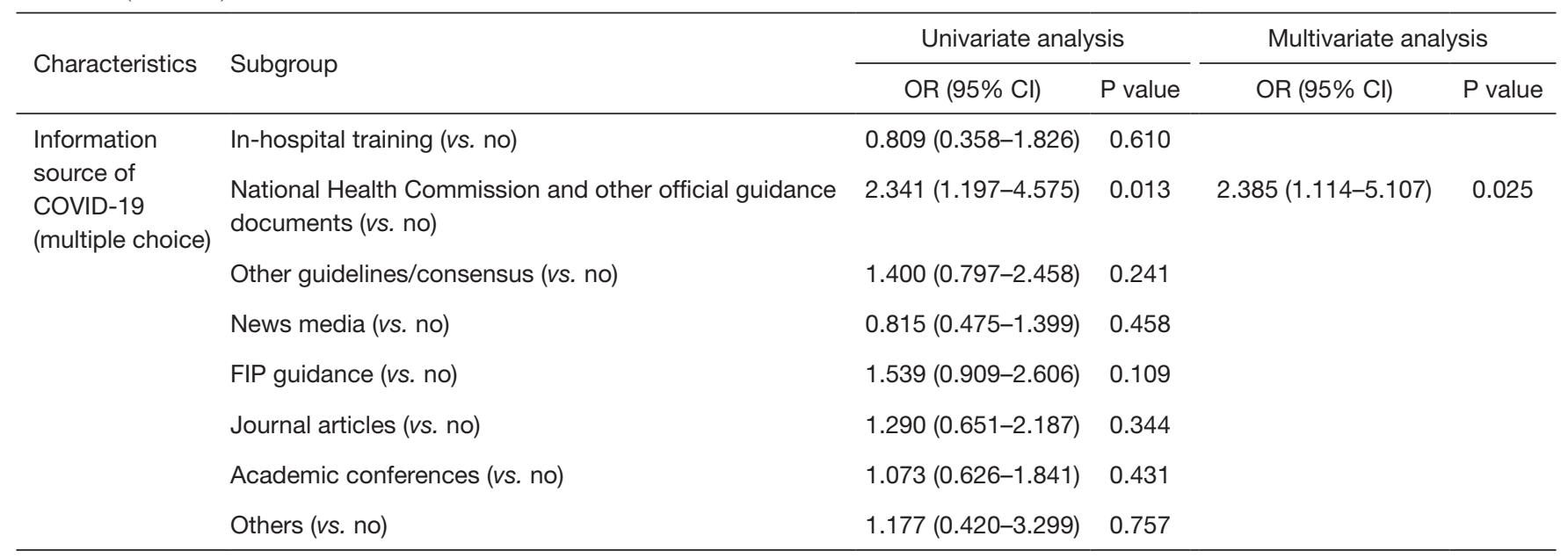

COVID-19, coronavirus disease 2019; OR, odds ratio; Cl, confidence interval.

pharmacists is limited and remains to be fully understood. In this study, we assessed the implementation of FIP guidance through a survey of the knowledge, attitudes, and practices of representative pharmacists. Most pharmacists were shown to have sufficient knowledge of transmission routes and clinical treatment for COVID-19, as well as positive attitudes towards their roles and actions. About half of the cohort were qualified in the practices of prevention and control measures, risk factor control, and pharmacist's advice. Several factors were revealed as having impact on pharmacists' KAP, such as whether they were participating in COVID-19 work, working content, and information source.

Most respondents $(67.51 \%)$ showed appropriate knowledge regarding transmission routes and clinical treatment, which is consistent with studies in other countries, such as Lebanon, Turkey, Vietnam, and Pakistan (9,13-15). Over $60 \%$ had positive attitudes towards pharmacists' roles and actions. However, pharmacists referred to other guidelines or consensus more than FIP guidance, including information and guidance from the Chinese National Health Commission (16) and those developed by Chinese associations and institutions $(17,18)$. Authorized guidance of COVID-19 was a positive impact factor to the attitudes of pharmacist towards COVID-19.

The accessibility, validity, adaptability, applicability, and usability were considered important factors to guidance implementation $(6,19,20)$. Mandatory requirements and supervision by authorities also played an essential role. During the COVID-19 pandemic, it was required that all medical staff should learn the authorized guidance of COVID-19. Thus, pharmacists obtaining COVID-19 information from official guidance documents may have better knowledge and attitudes.

Effective prevention measures and infection risk monitoring for pharmacists are necessities during the COVID-19 pandemic, which can reduce the risk of infection for both themselves and others (21). They must maintain and promote good hygiene conditions, take prevention measures such as wearing disposable gloves, protective clothing, eye protection, and masks, and maintain appropriate social distance with patients and other healthcare staff $(15,21,22)$. In our study, $69.62 \%$ of pharmacists took adequate prevention measures against workplace infections. The result is similar to the study in Henan, where $89.7 \%$ of healthcare staff took effective measures (23). However, it has been reported that as many as $72.4 \%$ of pharmacists in Jordan believed that keeping a distance of half a meter from COVID-19 patients can effectively prevent viral transmission (24). Thus, it is still necessary to seek an understanding of pharmacists' behavior around the world to determine barriers for the implementation of medical guidance.

As for practice to promote treatment of COVID-19, although some antiviral agents such as interferon- $\alpha$, ribavirin, arbidol and chloroquine phosphate were observed to have therapeutic effect on COVID-19 based on available clinical studies, there is still no specific therapeutic drug approved for COVID-19 worldwide (25). Thus, pharmacists are encouraged to cooperate with clinicians to closely 


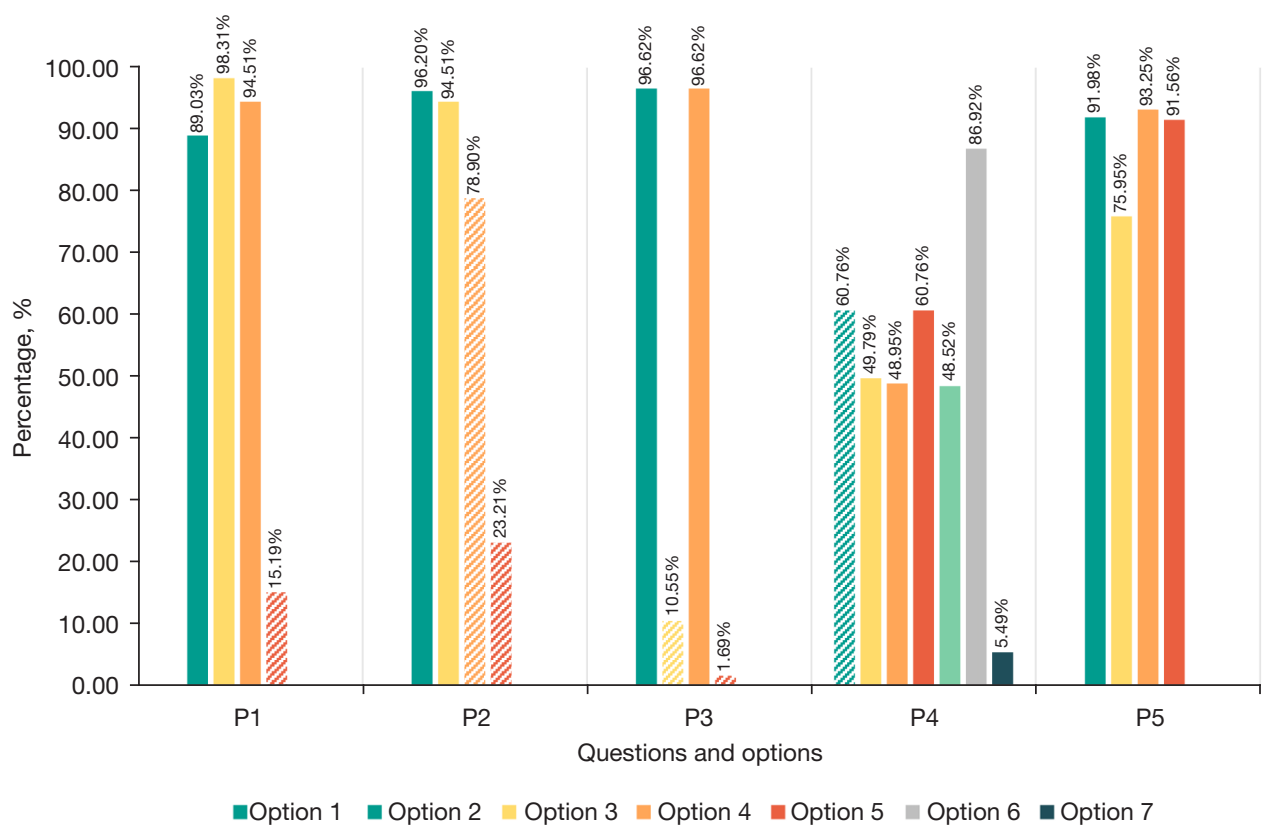

Figure 3 Results of practices. P1—which statement about personal prevention is correct: (correct) keep short or tied hair, avoid growing beards, avoid wearing jewelry, watches, and makeup; (correct) wear a mask at work to prevent self-infection and further transmission; (correct) wear gloves, masks, protective masks, or goggles, and protective clothing when necessary during work; no need to wear a respirator when participating in operations that may generate aerosols. P2-which statement about cleaning and disinfection is correct: (correct) frequent hand hygiene and facial cleansing; (correct) disinfect the surface of any objects that patients or the public may touch; UV radiation, heat, $75 \%$ ethanol, chlorine-containing disinfectant, and chlorhexidine are all suitable for disinfection; $75 \%$ ethanol can be used to disinfect large areas such as air. P3-which of the following statement is correct: (correct) keep a distance of 1 to 2 meters from the patient and the public; close contact with others such as hugging and shaking hands will not increase the risk of infection; (correct) when coughing or sneezing, cover the mouth and nose with a clean tissue or the elbows; none of the above is correct. P4—which of the following disinfectants can effectively kill the virus: chlorhexidine; (correct) chlorine dioxide; (correct) disinfectant whose active ingredient is iodine (0.5\%); (correct) hydrogen peroxide disinfectant; (correct) ethylene oxide; (correct) alcohol-based quick-drying hand sanitizer; others. P5—which of the following statements about COVID-19 infection risk monitoring and pharmacist recommendations for patients is correct: (correct) the pharmacist should monitor the patient's infection risk based on the patient's clinical symptoms (such as cough, fever, or dyspnea) and epidemiological history (contact with confirmed or suspected cases and/or travel history to affected areas), and provide targeted intervention measures; (correct) for patients with clinical symptoms and without recent epidemiological history, pharmacists should recommend strict home isolation for at least 14 days; (correct) for patients who have not clinical symptoms and conform to the epidemiological history, pharmacists should recommend strict home isolation for at least 14 days. If symptoms occur during the isolation period, they should seek medical attention in time; (correct) for patients who have clinical symptoms and conform to the epidemiological history, pharmacists should advice proper prevention and timely medical treatment for testing and follow-up diagnosis and treatment.

monitor and evaluate the medication safety and efficacy.

To the best of our knowledge, our study was the first survey to explore the implementation of FIP guidance on COVID-19. The status of pharmacists' adherence and barriers of FIP guidance were analyzed and identified. However, our study had a few limitations that need to be addressed in further studies. Firstly, the study sample was relatively small and covered only mainland China, and the KAP of pharmacists from other regions should be considered. Secondly, this was a self-reported online survey through WeChat, face-to-face interviews might yield more information towards a better understanding of the implementation of the guidance. Due to unknown number of duplicate people in different WeChat groups, we did not know the number of nonresponse and the response rate was not calculated. Thirdly, bias cannot be excluded due to the 
Table 4 Logistic regression for being qualified in practices

\begin{tabular}{|c|c|c|c|c|c|}
\hline Characteristics & Subgroup & \multicolumn{2}{|c|}{ Univariate analysis } & \multicolumn{2}{|c|}{ Multivariate analysis } \\
\hline Gender & Male (vs. female) & $1.168(0.673-2.029)$ & 0.581 & 1.057 (0.566-1.974) & 0.861 \\
\hline \multirow[t]{2}{*}{ Job title } & Primary and below & $0.846(0.450-1.587)$ & 0.602 & $0.974(0.407-2.329)$ & 0.952 \\
\hline & Junior & Reference & & Reference & \\
\hline \multirow{4}{*}{$\begin{array}{l}\text { Education } \\
\text { background }\end{array}$} & College and below & $0.266(0.072-0.988)$ & 0.048 & $0.718(0.143-3.599)$ & 0.687 \\
\hline & Bachelor & Reference & & Reference & \\
\hline & Master & $1.374(0.767-2.461)$ & 0.286 & 1.205 (0.585-2.483) & 0.613 \\
\hline & Doctor & $1.996(0.791-5.036)$ & 0.143 & 1.660 (0.520-5.293) & 0.392 \\
\hline \multirow{2}{*}{$\begin{array}{l}\text { Job } \\
\text { responsibility }\end{array}$} & Pharmacy administrator & $0.815(0.413-1.611)$ & 0.557 & $0.788(0.327-1.899)$ & 0.595 \\
\hline & Others & $0.694(0.250-1.929)$ & 0.484 & 0.925 (0.279-3.072) & 0.899 \\
\hline \multirow[t]{5}{*}{ Working years } & $1-5$ & $1.133(0.551-2.331)$ & 0.734 & $1.332(0.570-3.111)$ & 0.508 \\
\hline & $6-10$ & Reference & & Reference & \\
\hline & $11-15$ & 1.249 (0.596-2.618) & 0.556 & $1.254(0.535-2.938)$ & 0.603 \\
\hline & $16-20$ & $0.971(0.359-2.629)$ & 0.954 & $1.156(0.322-4.149)$ & 0.824 \\
\hline & $\geq 21$ & $0.694(0.330-1.459)$ & 0.335 & $0.693(0.209-2.304)$ & 0.550 \\
\hline $\begin{array}{l}\text { Job position } \\
\text { (multiple choice) }\end{array}$ & General clinic (vs. no) & $0.688(0.402-1.176)$ & 0.172 & $1.371(0.596-3.154)$ & 0.458 \\
\hline COVID-19 work & Participation (vs. no) & $2.202(1.107-4.381)$ & 0.024 & 2.194 (1.008-4.776) & 0.048 \\
\hline \multirow{7}{*}{$\begin{array}{l}\text { Working content } \\
\text { of COVID-19 } \\
\text { (multiple choice) }\end{array}$} & Drug supply and guarantee (vs. no) & $1.185(0.704-1.996)$ & 0.523 & & \\
\hline & Pharmacy information support (vs. no) & $0.996(0.587-1.690)$ & 0.989 & & \\
\hline & Drug dispensation (vs. no) & $1.288(0.757-2.190)$ & 0.351 & & \\
\hline & Drug evaluation (vs. no) & $1.412(0.658-3.030)$ & 0.376 & & \\
\hline & Disinfectant preparation (vs. no) & $1.300(0.546-3.093)$ & 0.553 & & \\
\hline & Guidelines/consensus development (vs. no) & $0.369(0.112-1.212)$ & 0.100 & & \\
\hline & Others (vs. no) & $1.286(0.732-2.257)$ & 0.381 & & \\
\hline
\end{tabular}

Table 4 (continued) 
Table 4 (continued)

\begin{tabular}{|c|c|c|c|c|c|}
\hline Characteristics & Subgroup & \multicolumn{2}{|c|}{ Univariate analysis } & \multicolumn{2}{|c|}{ Multivariate analysis } \\
\hline \multirow{5}{*}{$\begin{array}{l}\text { Information } \\
\text { source of } \\
\text { COVID-19 } \\
\text { (multiple choice) }\end{array}$} & In-hospital training (vs. no) & $1.530(0.696-3.363)$ & 0.290 & & \\
\hline & $\begin{array}{l}\text { National Health Commission and other official guidance } \\
\text { documents (vs. no) }\end{array}$ & $0.776(0.399-1.507)$ & 0.453 & & \\
\hline & FIP guidance (vs. no) & $1.247(0.749-2.077)$ & 0.396 & & \\
\hline & Journal articles (vs. no) & $1.390(0.832-2.324)$ & 0.209 & & \\
\hline & Academic conferences (vs. no) & $1.841(1.081-3.135)$ & 0.025 & $1.700(0.943-3.065)$ & 0.078 \\
\hline
\end{tabular}

COVID-19, coronavirus disease 2019; OR, odds ratio; Cl, confidence interval.

nature of convenience sampling; thus, stratified sampling may strengthen sample representativeness.

In addition to strengthening the usability and applicability of such guidelines, it is encouraged to fully involve the knowledge, attitudes, and relevance of target users in the future directives. It is also important to integrate local policy to gain support and promotion from the relevant authorities during guidance implementation (26).

\section{Conclusions}

Our study revealed an appropriate level of knowledge, attitudes, and practices towards COVID-19 among pharmacists in mainland China, which indicated that the FIP guidance has a certain degree of dissemination and implementation in China. However, the implementation of guidelines can be improved through effective actions directed towards impact factors.

\section{Acknowledgments}

We would like to express our gratitude to all pharmacists who responded to our questionnaire. We also feel grateful for Prof. Shao Lin from School of Public Health, University at Albany, State University of New York for help with editing and Dr. Lin Zhuo from the Research Center of Clinical Epidemiology, Peking University Third Hospital for consultation.

Funding: The study is funded by the National Key R\&D
Program of China (2020YFC2008305), and the National Natural Science Foundation of China (NSFC) (72104003, 72042013).

\section{Footnote}

Reporting Checklist: The authors have completed the SURGE reporting checklist. Available at https://dx.doi. org/10.21037/atm-21-4157

Data Sharing Statement: Available at https://dx.doi. org/10.21037/atm-21-4157

Conflicts of Interest: All authors have completed the ICMJE uniform disclosure form (available at https://dx.doi. org/10.21037/atm-21-4157). The authors have no conflicts of interest to declare.

Ethical Statement: The authors are accountable for all aspects of the work in ensuring that questions related to the accuracy or integrity of any part of the work are appropriately investigated and resolved. All procedures performed in this study involving human participants were in accordance with the Declaration of Helsinki (as revised in 2013). The study was approved by institutional ethics board of the Peking University Third Hospital (No.: IRB00006761-M2020299). The online voluntary and anonymous questionnaire secured the confidentiality of the participants, and did not collect any identity-exposing 
information of the participants.

Open Access Statement: This is an Open Access article distributed in accordance with the Creative Commons Attribution-NonCommercial-NoDerivs 4.0 International License (CC BY-NC-ND 4.0), which permits the noncommercial replication and distribution of the article with the strict proviso that no changes or edits are made and the original work is properly cited (including links to both the formal publication through the relevant DOI and the license). See: https://creativecommons.org/licenses/by-nc-nd/4.0/.

\section{References}

1. Lurie N, Keusch GT, Dzau VJ. Urgent lessons from COVID 19: why the world needs a standing, coordinated system and sustainable financing for global research and development. Lancet 2021;397:1229-36.

2. International Pharmaceutical Federation (FIP). FIP CALL TO ACTION: To support pharmacists and pharmacy workers on the coronavirus/COVID-19 frontline. Available online: https://www.fip.org/files/ content/publications/2020/FIP-call-to-action-to-supportpharmacists-and-pharmacy-workers-on-the-coronavirusCOVID-19-frontline.pdf. Accessed: June 1st 2021.

3. International Pharmaceutical Federation (FIP). COVID-19: Guidelines For Pharmacists and the Pharmacy Workforce (Updated 14 JULY 2020). Available online: https://www.fip.org/file/4729. Accessed: May 18th 2021.

4. Graham B. Clinical practice guidelines: what are they and how should they be disseminated? Hand Clin 2014;30:361-5, vii.

5. Hetrick SE, Thompson A, Yuen K, et al. Is there a gap between recommended and 'real world' practice in the management of depression in young people? A medical file audit of practice. BMC Health Serv Res 2012;12:178.

6. Gagliardi AR, Brouwers MC, Palda VA, et al. How can we improve guideline use? A conceptual framework of implementability. Implement Sci 2011;6:26.

7. Sousa Pinto G, Hung M, Okoya F, et al. FIP's response to the COVID-19 pandemic: Global pharmacy rises to the challenge. Res Social Adm Pharm 2021;17:1929-1933.

8. Zeenny RM, Dimassi A, Sacre H, et al. A cross-sectional survey on community pharmacists readiness to fight COVID-19 in a developing country: knowledge, attitude, and practice in Lebanon. J Pharm Policy Pract 2021;14:51.

9. Zeenny RM, Ramia E, Akiki Y, et al. Assessing knowledge, attitude, practice, and preparedness of hospital pharmacists in Lebanon towards COVID-19 pandemic: a crosssectional study. J Pharm Policy Pract 2020;13:54.

10. Tesfaye ZT, Yismaw MB, Negash Z, et al. COVID-19Related Knowledge, Attitude and Practice Among Hospital and Community Pharmacists in Addis Ababa, Ethiopia. Integr Pharm Res Pract 2020;9:105-12.

11. Launiala A. How much can a KAP survey tell us about people's knowledge, attitudes and practices? Some observations from medical anthropology research on malaria in pregnancy in Malawi. Anthropol Matters J 2009;11:1-13.

12. Zhao RS, Yang YH, Yang L, et al. Coronavirus SARSCoV-2 outbreak: Information and Guidelines for Pharmacists and the Pharmacy Workforce. Chin Pharm J 2020;55:249-67.

13. Kara E, Demİrkan K, Ünal S. Knowledge and Attitudes Among Hospital Pharmacists About COVID-19. Turk J Pharm Sci 2020;17:242-8.

14. Huynh G, Nguyen T, Tran V, et al. Knowledge and attitude toward COVID-19 among healthcare workers at District 2 Hospital, Ho Chi Minh City. Asian Pacific Journal of Tropical Medicine 2020;13:260-5.

15. Saqlain M, Munir MM, Rehman SU, et al. Knowledge, attitude, practice and perceived barriers among healthcare workers regarding COVID-19: a cross-sectional survey from Pakistan. J Hosp Infect 2020;105:419-23.

16. National Health Commission of the People's Republic of China. Diagnosis and Treatment Protocol for COVID-19 Patients (Tentative 8th Edition). Available online: http:// en.nhc.gov.cn/2020-09/07/c_81565.htm. Accessed: June 1 st 2021.

17. Zhao RS, Yang YH, Yang L, et al. Coronavirus 2019nCoV Infection: Expert Consensus on Guidance and Prevention Strategies for Hospital Pharmacists and the Pharmacy Workforce. Chin Pharm J 2020;55:268-77.

18. Zhang Y, Chen X, Zhan BK, et al. Expert Consensus on Rational Drug Use in Clinical Practice for COVID-19. Chin J Hosp Pharm 2020;40:593-605.

19. Shiffman RN, Dixon J, Brandt C, et al. The GuideLine Implementability Appraisal (GLIA): development of an instrument to identify obstacles to guideline implementation. BMC Med Inform Decis Mak 2005;5:23.

20. Gagliardi AR, Marshall C, Huckson S, et al. Developing a checklist for guideline implementation planning: review and synthesis of guideline development and implementation advice. Implement Sci 2015;10:19.

21. Cadogan CA, Hughes CM. On the frontline against 
COVID-19: Community pharmacists' contribution during a public health crisis. Res Social Adm Pharm 2021;17:2032-5.

22. Centers for Disease Control and Prevention (CDC). COVID-19. Available online: https://www.cdc.gov/ coronavirus/2019-ncov/index.html. Accessed: June 17th 2021.

23. Zhang M, Zhou M, Tang F, et al. Knowledge, attitude, and practice regarding COVID-19 among healthcare workers in Henan, China. J Hosp Infect 2020;105:183-7.

24. Abdel Jalil M, Alsous MM, Abu Hammour K, et al. Role of Pharmacists in COVID-19 Disease: A

Cite this article as: Yi ZM, Song ZW, Li XY, Hu Y, Cheng YC, Wang GR, Zhao RS. The implementation of a FIP guidance for COVID-19: insights from a nationwide survey. Ann Transl Med 2021;9(18):1479. doi: 10.21037/atm-21-4157
Jordanian Perspective. Disaster Med Public Health Prep 2020;14:782-8.

25. Song Z, Hu Y, Zheng S, et al. Hospital pharmacists' pharmaceutical care for hospitalized patients with COVID-19: Recommendations and guidance from clinical experience. Res Social Adm Pharm 2021;17:2027-31.

26. Jin YH, Deng T, Zeng XT, et al. Methodology for Clinical Practice Guidelines--Implementation Tools of Guidelines. Chin J Evidence-Based Cardiovasc Med 2019;11:1157-61.

(English Language Editor: J. Jones) 